\section{FUTURE SRJ}

FUTURE STUDIES RESEARCH JOURNAL: TRENDS AND STRATEGIES
Profuturo: Future Studies Program

Scientific editor: James Terence Coulter Wright

Evaluation: Double Blind Review pelo SEER/OJS

Revision: Grammatical, normative and layout.

INCREASE IN INTERNET ACCESS BY YOUNGSTERS FROM BRAZIL'S PYRAMID BASE AND ITS SINGULARITIES

\author{
Ian de Freitas \\ Fundação Instituto de Administração \\ ian.freitas@gmail.com \\ Daniel Estima de Carvalho \\ Fundação Instituto de Administração \\ danielc@fia.com.br
}

\title{
ABSTRACT
}

This article examines the unique behavior characteristics of internet users in Brazil, such as high engagement in social networks, the world's largest blogging category penetration among internet users as well as other phenomena and analyzes how the entry of young consumers from the base of the pyramid leverage these particularities and changes fundamentally the internet access points, content origin, discovery relevance $\&$ production and how those changes fundamentally change the relevance of online categories and services in Brazil.

Key-words: Internet. Brazil. Online market. Bottom of pyramid. Social networks. User generated content. Blogs. 


\section{RESUMO}

Este artigo analisa as singularidades de comportamento de usuários de internet no Brasil, como o alto engajamento em redes sociais, liderança na penetração mundial da categoria de blogs, entre outros fenômenos. Analisa, também, como a entrada de consumidores jovens das classes sociais da base da pirâmide amplifica este processo e altera fundamentalmente os canais de acesso online, origem, descoberta, relevância e produção de conteúdo e como essas mudanças alteram a relevância de categorias e serviços online no Brasil.

Palavras-chave: Internet. Brasil. Mercado online. Classe C. Redes sociais. Conteúdo gerado por consumidores. Blogs. 


\section{INTRODUCTION}

Over the past few years, Brazil has become an on-line world-wide power having ranked, by the end of 2011, the seventh position amongst countries featuring the world's largest number of web surfers, ahead of countries such as France and the UK and presenting a 16\% annual growth, far more than that registered by developed countries.

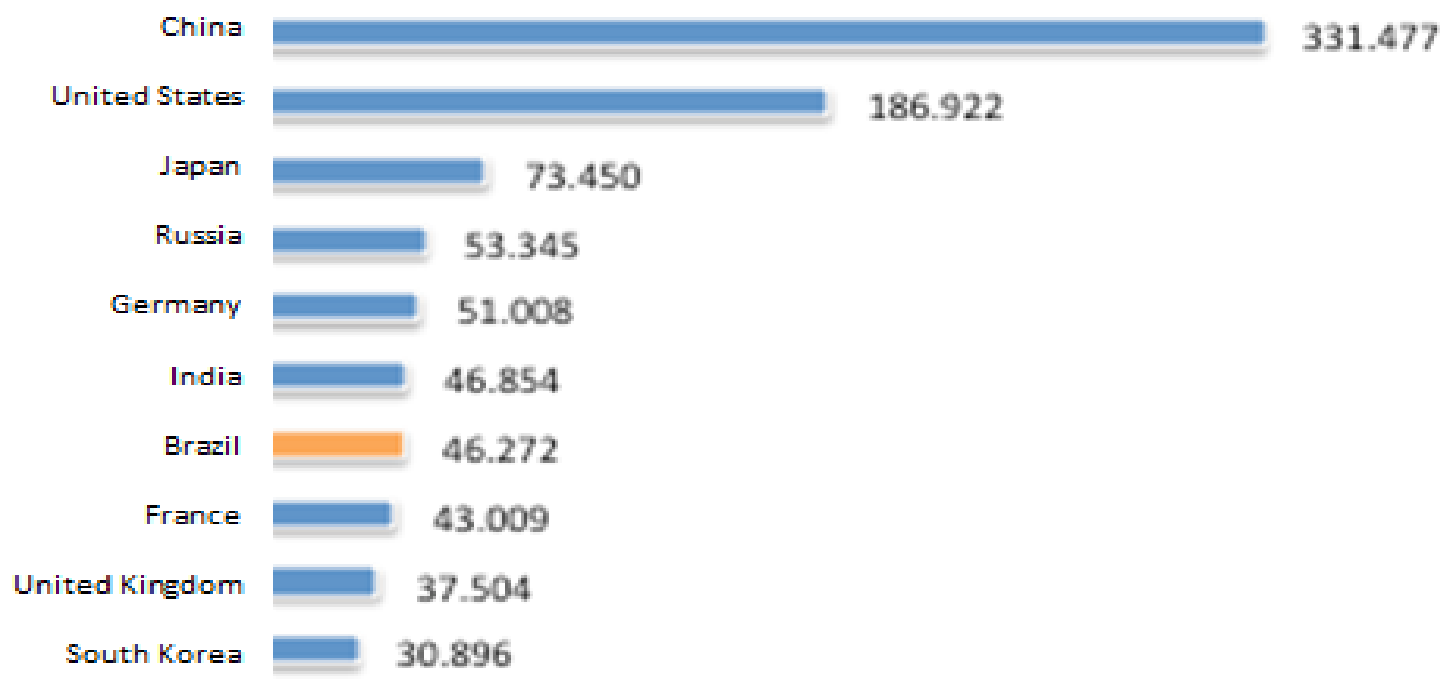

\section{Graph 1: Number of users in millions amongst the top 10 on-line populations}

Source: Comscore (2011).

According to Comscore (2011), one of Brazil's peculiarities, is that the local consumer is younger than that deemed world average. Whilst throughout the world consumers up to the age of 34 represent $51 \%$ of the on-line population, in Brazil youngsters represent $" 60 \%$ and are primarily held responsible for internet expansions over the last few years. Likewise, recent social and consumption ascension of Brazil's C class - a process that established this social level as being that dominant in the country- provided this group with access to internet, technologies and information, until then solely available to $A$ and $B$ social class levels.

According to Comscore (2011) data, Brazil's internet counted on more than 46 million residential and workplace consumers and in recent years staged 
unique site and on-line service consumption preferences as compared to the rest of the western world. Orkut is a widely renowned example of Brazilian internet peculiarities but local eccentricities are not limited to this social media tool.

Brazilian web surfers present an above average affinity with participative services which offer the possibility of promoting ecosystems, sharing knowledge and of transforming themselves into producers, constructors and catalyzers of information and the its transformation.

Thanks to the internet, the pyramid base found its voice and this inclusion process democratizes access and expands the generation of information, shaping the relevance of both content and services on the Brazilian web. This paper poses to provide an in-depth understanding of the perception of reality, cultural aspects and needs of the pyramid's base population of youngsters and how these needs shape into the consumption of on-line service categories.

By means of quantitative data collected by research institutes concerning the use of sites in Brazil and via a quantitative/qualitative exploratory survey, this paper attempts to build the necessary knowledge to ensure the comprehension of changes that shall in the future render the Brazilian consumer's behavior over the internet yet more complex.

\section{BIBLIOGRAPHICAL REVISION}

The introduction of the internet and evolution of its services gave rise to a new paradigm that became known as Web 2.0 as coined by Peter O'Reilly (2004) and defined by the same as being the shift to internet as a platform, reaping network effects to improve itself the more it is used by surfers, employing collective intelligence. This change fundamentally altered the unilateral content consumption web - mirror of other traditional medias such as TV, magazines and newspapers - to transform the internet into a participative platform through which user collaboration helps build and redefine information.

Web 2.0 - built as a scalable platform featuring the ability to develop ecosystems and transform its consumers into producers of content and information - ended up developing the "virtual presence of humanity for its own 
sake" (Lévy, 1999). The concept then became tangible by means of blogs and social networks amongst many other on-line services whereby the consumer himself generates content that others shall consume. Web 2.0 found in the pyramid's base of youngsters a captive audience that produces atypical phenomena. Several cases have demonstrated the eccentricity of the use of Brazil's internet whereby Orkut, a social network developed by a Google engineer in 2004, is deemed most emblematic. Orkut not only became the most relevant social network in Brazil when MySpace was the predominant western service but also featured amongst the top three Brazilian internet destinations, reaching over $80 \%$ of total surfers.

After the ascension and fall of MySpace, Facebook established itself as leader at developed countries and featured in 2012, over 800 million unique users per month in the world. Until a short while ago however, the situation was quite different in Brazil: Orkut remained unshaken as leading social network and it was only in December 2011 - seven years after its ideation - that it lost its leading position on the local market. Furthermore, in mere six months, Brazil became the second largest country in terms of unique Facebook users and according to Social Bakers (s.d.). Yahoo! Replies and Twitter are also examples of local peculiarities. In both, Brazil featured as the third largest country in the world - with 19and 12 million users per month in 2012 respectively - to the extent that Yahoo! Replies became greater than the category world leader Wikipedia.
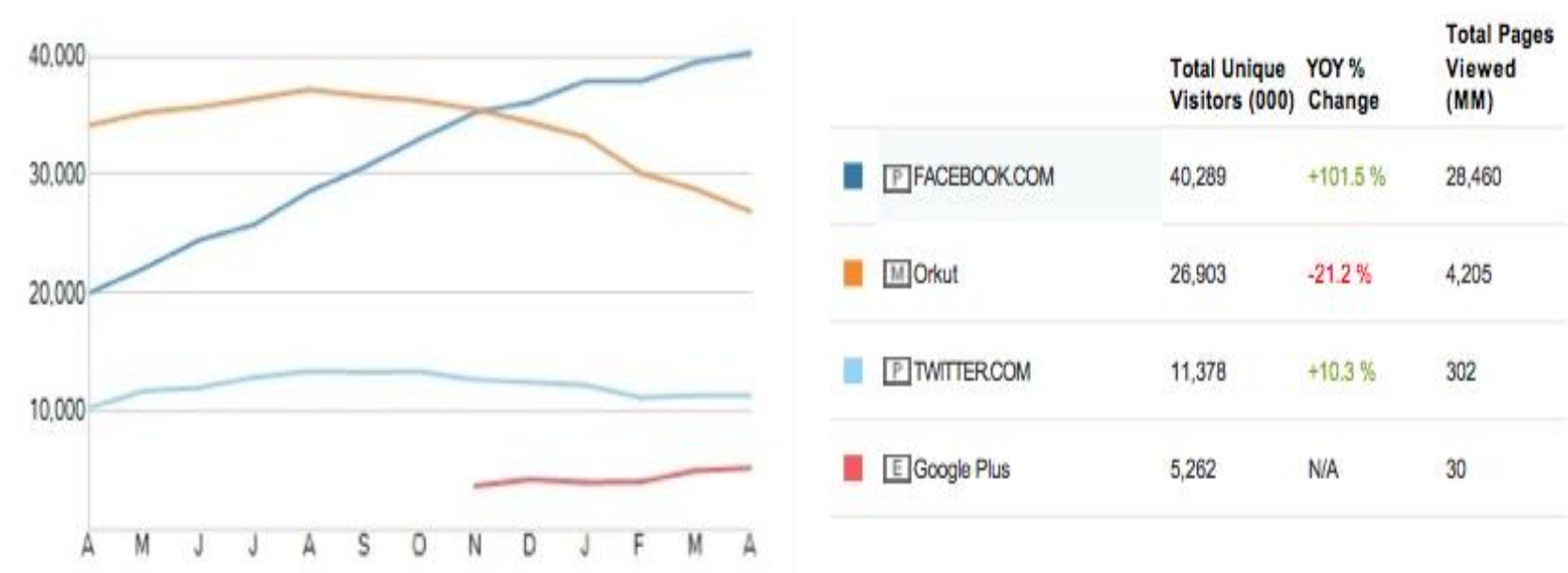

\section{Graph 2: Evolution of single Facebook, Orkut, Google+ and Twitter users in Brazil between April 2011 and April 2012}

Source: Comscore (2011). 
Personal relations over the Brazilian internet still feature additional peculiarities: surveys conducted by TNS Digital Life (2010) demonstrated that Brazil is the second largest country in the world in number of social network friends given that for every consumer surveyed, each featured an average of 231 friends, only lagging behind Malaysia where findings indicated an average number of 233 acquaintances.

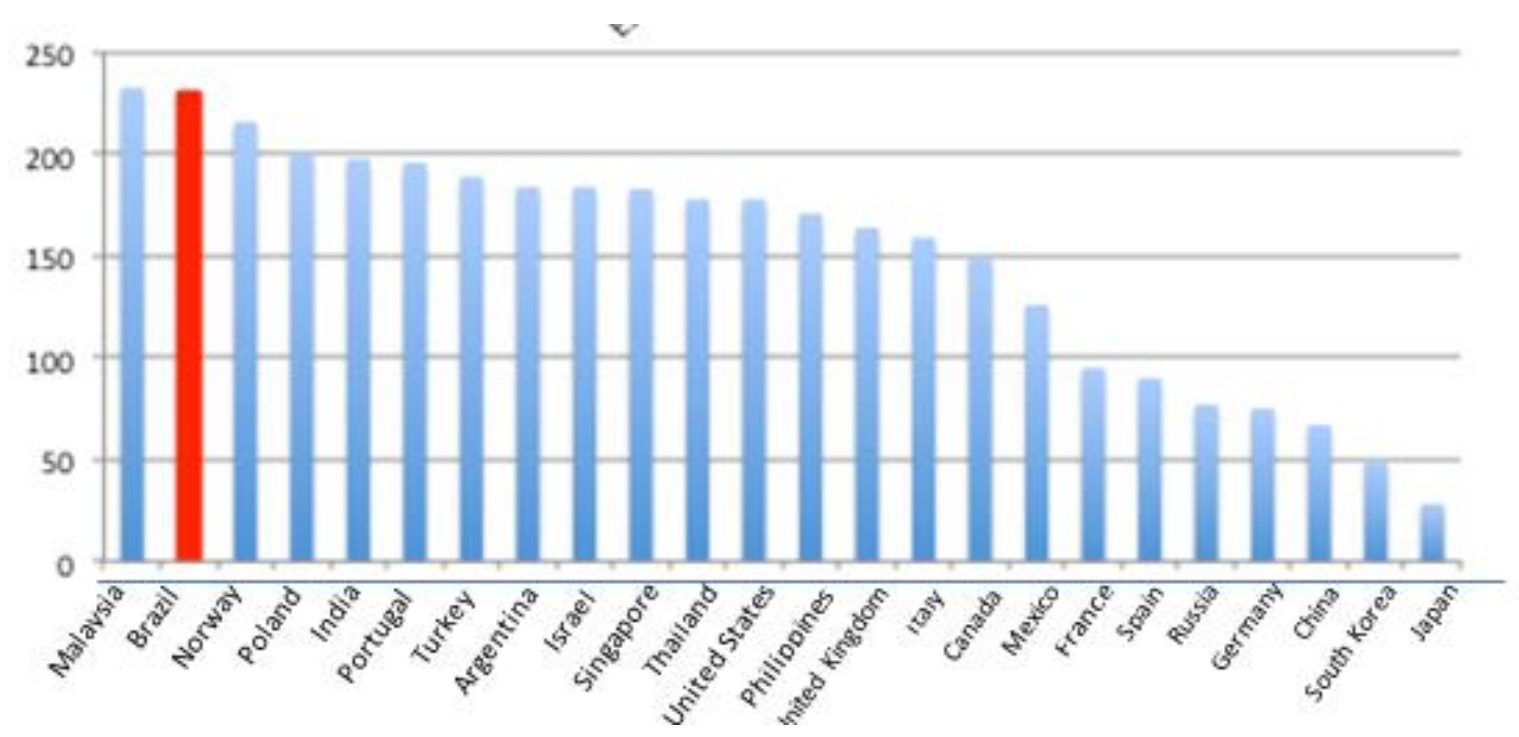

Graph 3: Number of social network friends in Brazil and in the world

Source: TNS Digital Life (2010).

A constant theme of debate amongst journalists, the blog category established itself as an alternative before the country's media conglomerates. According to Ramonet (2012) this is due to the existence of a global process in course involving the erosion of the credibility of these conglomerates that express an increasingly narrower plurality of opinions.

Credibility erosion occurred in Brazil to an outstanding extent. According to a joint survey conducted by BBC/Reuters/Media Center (2005) at the time there was a high level of dissatisfaction with the quality and credibility of traditional media in Brazil as compared to that of other surveyed countries: $45 \%$ did not trust news was precise, demonstrating a high level of skepticism in relation to journalism itself in Brazil, whilst 44\% claimed to have stopped reading at least one media during the previous year for having lost trust in the same, yet another leading percent figure amongst participating countries. 


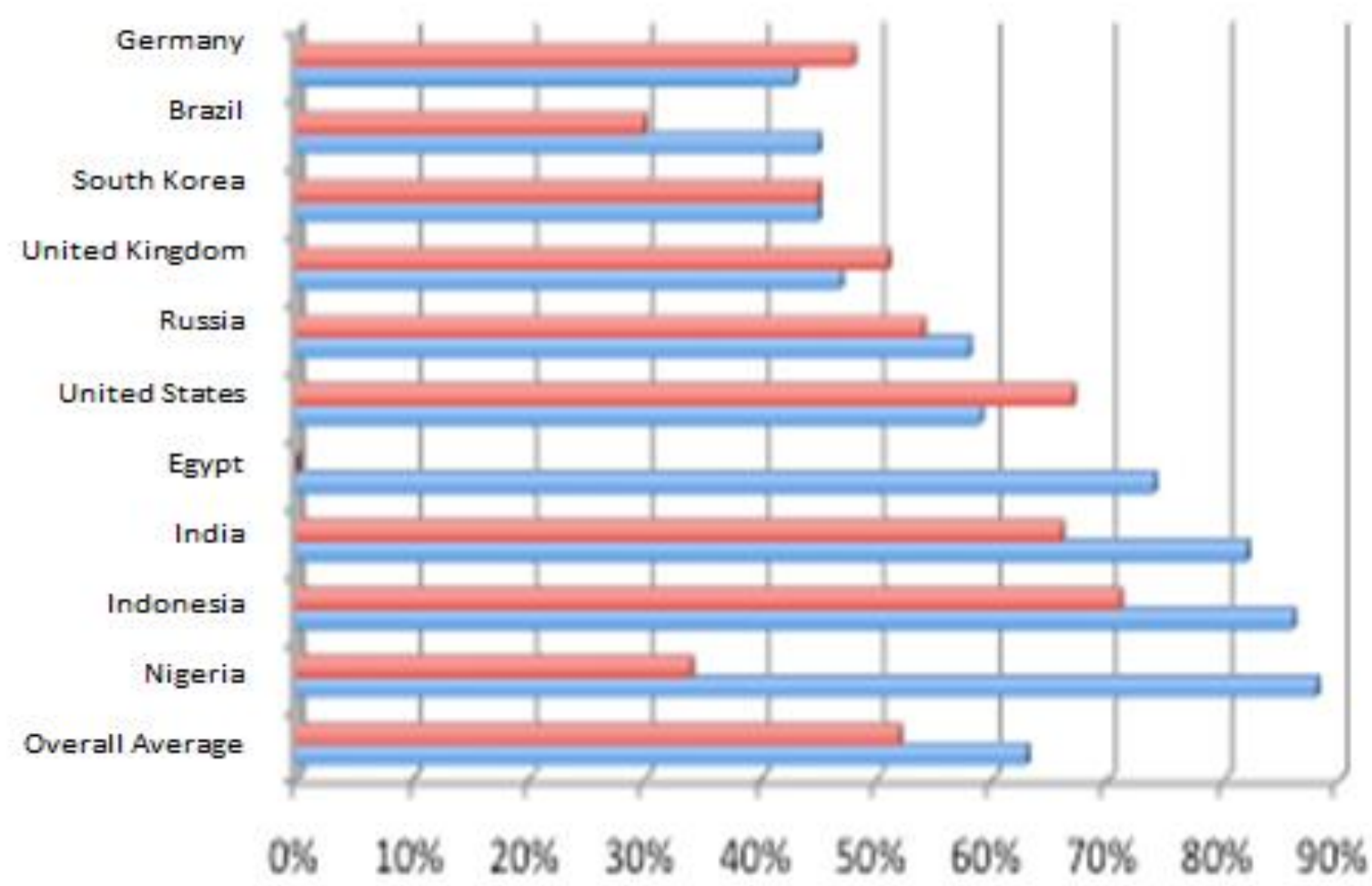

Government Media

\section{Graph 4: Trust in media and in the government}

Source: BBC/Reuters/Media Center (2005).

Both Brazil and South Korea which presented the greatest lack of confidence in media (only $45 \%$ worth of trust) are precisely the countries that feature top world reach in the blog category, whilst Brazil remains world leader in terms of outreach within total on-line populations.

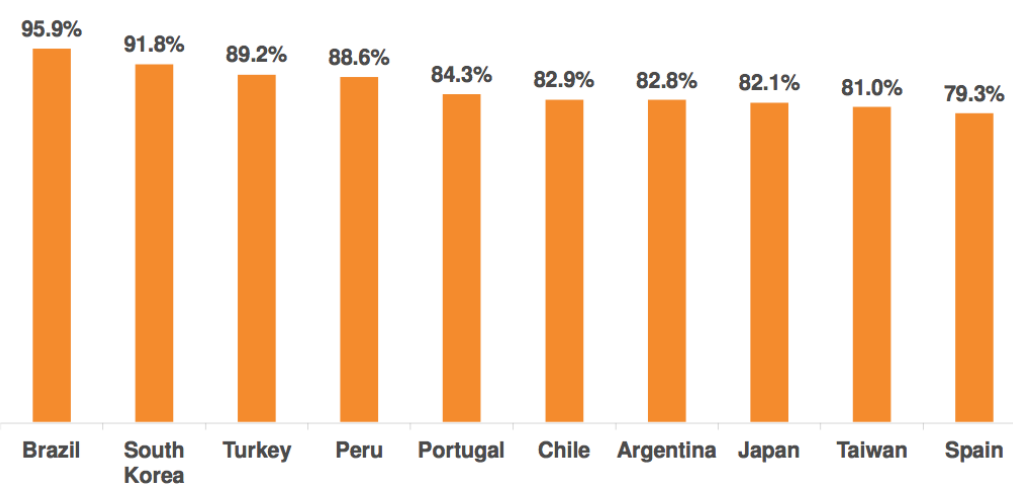

Graph 5: \% outreach of unique users of the blog category amongst home/workplace internet users of the top 10 category leading countries Source: Comscore (2011). 
The mentioned erosion of credibility process is one of the prime reasons that led to the rise of blogs and reference sites. According to Lévy and Lemos (2010) these play a major role given that they develop bottom-up, via conversation, conflict and collaboration and are no longer obliged to contain their own, restricted perspective which is one of the aspects mentioned when it comes to traditional media. Thus, surfers may distribute and share their perception of the world on an entirely free basis, shaping a more extensive, ample and open vision of the world.

The high volume of human interactions over the Brazilian internet demonstrates that there is a local sharp and rampant trend towards virtualization of human relations over the internet. Tapscott (2009) outlines a theory as to cultural changes that resulted in such high virtualizations, something that is likewise observed in the US. According to the author, the baby boomer generation mostly expanded within rigid and hierarchic family structures whereby the role of the father was that of the patron, who should be strictly obeyed and the home environment in itself was full of rules and subject to control. This generation found its freedom beyond home frontiers where they could meet friends away from paternal authority and also featured a latent urge to grow and leave the parental home so as to conquer this kind of autonomy. However, once this generation had their own children, several changes took place in society such as the explosion of population and overcrowding of urban centers and consequent rise in violence. Within homes, cultural changes likewise took place such as the increase in the rate of divorce and consequent dissipation of the hierarchic environment.

These changes in turn enabled baby boomer children to have restricted access to outdoor activities given fear of violence and greater freedom within homes where they found new grounds for freedom: their own room which soon became a microcosm, a place where they enjoyed autonomy and freedom with little or no restriction. The room became the freeing space and internet offered a "virtual window" with access to the outside world, contact with friends and others, thus intensifying the virtualization of relations. 
Despite the fact that this study was conducted in light of changes that took place in North America (US and Canada), there are a number of similarities with Brazil given that process catalyzing changes of the kind also occurred in this country over the past few decades: increase in the rate of divorce, changes in family structures, demographic explosion, rapid overcrowding of urban centers without the consolidation of infrastructure or public policies aligned with the new reality and increases in violence indexes, increasing reclusion and reducing outdoor activities. Upper classes gave rise to a vast supply of closed condominiums and shopping centers as a safe and controlled outdoor leisure option. In as much as lower social class levels are concerned, the lack of infrastructure did not allow for the offering of leisure options at adequate levels neither did transportation infrastructure ease travel to existing outdoor activities. This also promoted reclusion at its own level and scale thus offering optimized conditions for the internet to become an entertainment and relationship alternative.

Surveys conducted in Brazil by Dossiê MTV \#3 (2004) - comprising a total number of 2.359 Brazilian men and women, aged between 15 and 30, of classes A, B and C who resided in São Paulo (Capital and interior of the State), Rio de Janeiro, Salvador, Brasília, Recife, Belo Horizonte and Porto Alegre - revealed that $71 \%$ has little or no desire to leave parental homes. This trend suggests the existence of a harmonious environment within homes and explains the virtualization of relationships, thus, one of the reasons why social networks are so strong on the domestic front.

Prahalad (2009) further mentions that pyramid base products and services must be different from those made available at developed markets, must challenge paradigms - and, as of an unprecedented perspective for the market that seeks them out - must not rise from existing experience gathered at developed countries. The author identifies a handful of ingredients for companies to be successful at the base of the pyramid all of which are closely related to the peculiarities of the on-line market, such as the need to generate an economy of scale - vital to cyberspace initiatives - given that the market dynamics requires companies to have an extensive audience. Furthermore, the author states that consumers of the base are sophisticated, adopt advanced technologies at a faster 
pace and that the internet is an arena for constant evolution and technological updating.

According to Prahalad (2009), given collaborative creation of solutions, consumers demand to be respected as co-ideators and not only as passive receptors, thus transforming themselves into micro-producers, one of Web 2.0 's characteristics. When one looks at the Brazilian internet's greatest hits - Orkut, Twitter, Facebook, Blogs, Yahoo! Replies -, it becomes evident that all offer platforms for the generation of content - a stage for micro-producers to demonstrate their skills and reap recognition. All these services place consumers in the spotlight as those who generate opinions and content. Yahoo! Replies for instance, allows any consumer to ask a question on-line which can be replied by any other consumer and the person that placed the query can choose, amongst all respondents that which he or she deems the best reply. This highlights the reality of Web 2.0 services at the individual level whereby consumers are replying and solving their queries amongst themselves, changing the structure of information and of its very sharing into something that is both collaborative and interactive.

Prahalad (2009) further adds that the ability to collaborate and that of integration in a more ample spectrum are far more relevant than that of investment. Check this out: before having an office in Brazil or local investments Twitter had already reached over 10 million users with a platform that enabled the collaborative ability to share information, thoughts and actions amongst its users.

Finally, there is the social recognition aspect. As Prahalad (2009) states, this is a universal need: when a consumer of the base obtains, for instance, a Casas Bahia credit card, it is deemed as form of social ascension. It is his ability to exercise buying power, of becoming a consumer and of having his identity defined. The same occurs over the internet when a surfer becomes a microproducer of on-line content or nurtures a persona at a social network, thinks, suggests and produces content and information. This need for acknowledgement resides amongst consumers of the base of the pyramid and is the prime ground for the sustainability of social networks in Brazil. 


\section{RESEARCH METHODOLOGY}

So as to investigate the hypothesis herein raised, an exploratory survey with an online quantitative/qualitative approach was conducted including 21 questions that attracted 142 Brazilian respondents from all social classes and age ranges enabling the comprehension of differences in terms of behavior, forms of internet access, values, cultural aspects, expectations and needs. The objective is to validate differences between young consumers of up to 24 years of age and of classes $C, D$ and $E$, comparing these to the overall Brazilian on-line population 's behavior.

The on-line research was conducted between May 10 and June 12, 2012. Social network users were interviewed and the invitation was sent to on-line communities within Facebook and Orkut. The survey was managed by the on-line QuestionPro tool which allowed users to submit on-line replies in an anonymous and safe manner. The most relevant results are hereinafter presented.

\section{RESEARCH RESULTS}

\subsection{AGE RANGE, GENDER AND FAMILY INCOME}

The under 24 years of age audience represents 35,82\% of the total number of survey respondents. In as much as gender is concerned, the researched group was homogeneous, comprising $49,62 \%$ women and $50,38 \%$ men. 


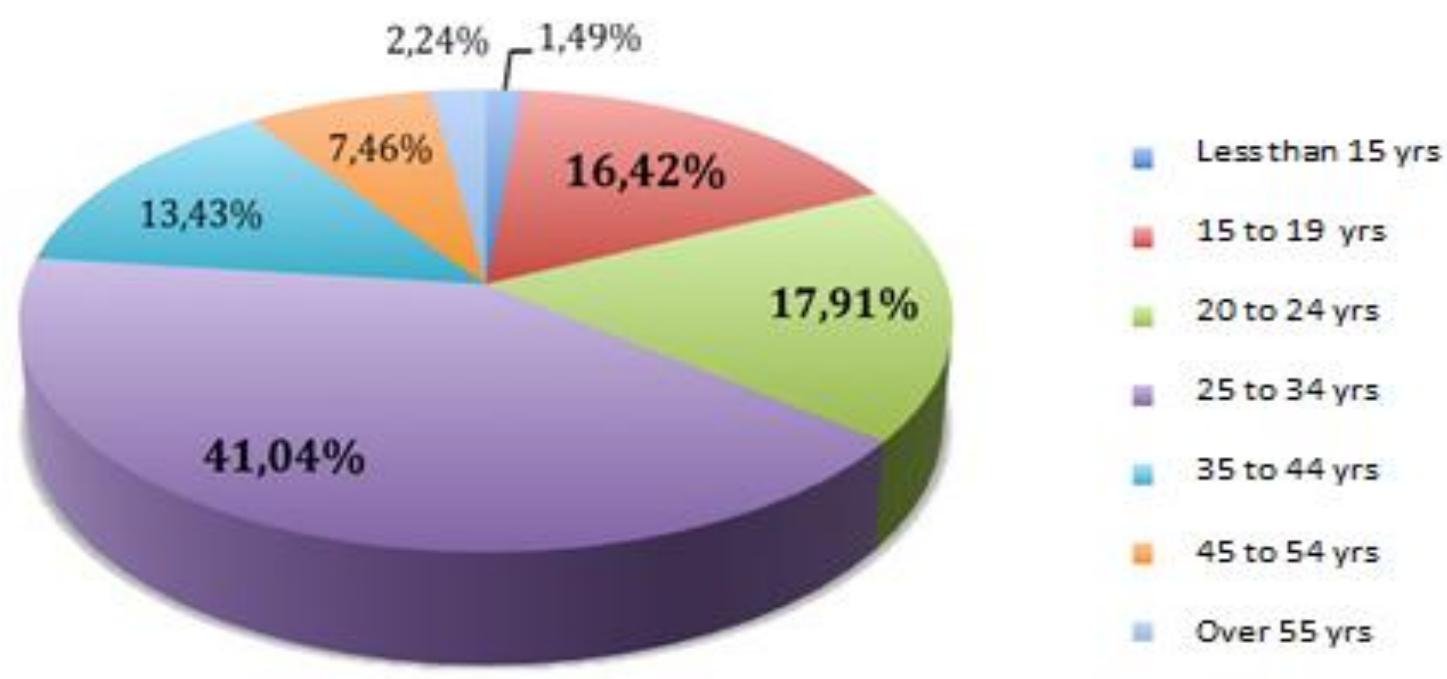

\section{Graph 6: Total Universe: Segmentation per Age Group}

Source: Elaborated by authors

To analyze segmentation per social level, FGV's (2012) segmentation standard was adopted and research focused on social levels C, D and E as a group, representing $49,72 \%$ of the total number of respondents.

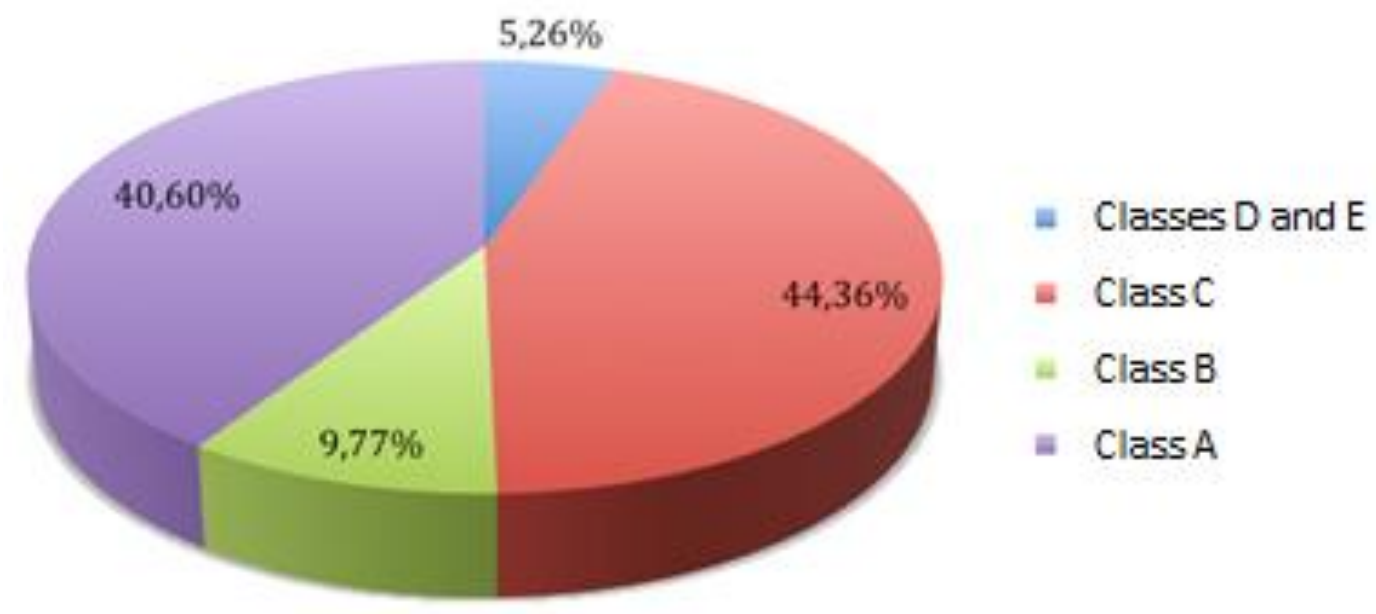

\section{Graph 7: Total Universe: Consolidated Segmentation per Social Level}

Source: Elaborated by authors 


\subsection{FROM WHERE INTERNET IS ACCESSED}

Findings indicate that mobile phones have already become the second option for internet access for all surveyed groups. Nevertheless, there is still a portion of social level C, D and E youngsters who do not own personal computers and who have to go to Lan Houses to access the internet. However, over the last couple of years, given the increase in both income and access to information technology and telephony products there has been an expansion of residential computers with internet access and, in an outstanding manner, a penetration of mobile phones with internet access within this segment, in comparison to the total universe's average figures.

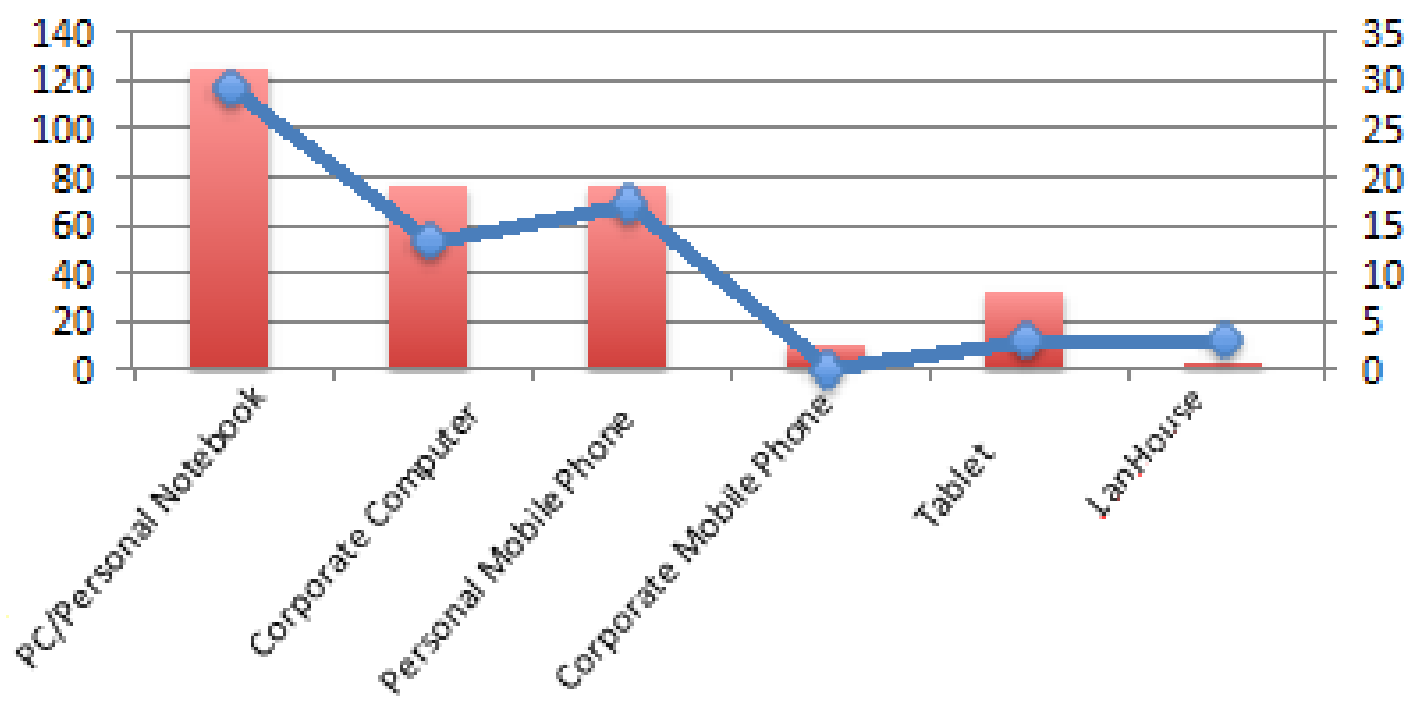

Total Universe

$\approx$ Class C, D and E youngsters

\section{Graph 8: Types of points of internet access employed: universe total and youngster group of $C, D$ and E social levels}

Anatel's May 2012 data indicates that there are 253 million active mobile phones in Brazil, an average of more than one device per inhabitant, thus becoming the technology with greatest ubiquity in the country and young consumers of the base of the pyramid are already using the device as a means to access the internet. Given its power of penetration, this technology may even become the main point of access to internet in Brazil as was the case in other countries undergoing development, such as India. 
Furthermore, surveyed persons aged between 25 and 34 years are those who most employ distinct points to access the internet (2,8 access points), closely followed by the 20 to 24 year old age group (2,7 access points). On average, these two groups access the internet at approximately $50 \%$ more locations than elders aged 45 or more (1,8 points). Results further demonstrate that people whose income range is up to $R \$ 1.000,00$ are who on average utilize only one location to access the internet $(1,3)$ and those with the greatest income range are who employ approximately three points of access $(3,2)$. People whose income ranges between $\mathrm{R} \$ 1.000,01$ and $\mathrm{R} \$ 10.000,00$ on average use two access locations.

\subsection{ON-LINE SERVICE CATEGORIES WITHOUT WHICH ONE CANNOT LIVE (UP TO 5)}

The point of the question was not to list all service categories used but rather to comprehend which consumers deem essential. To this effect, an idiosyncrasy was encountered between services deemed essential by the total universe and by young $C, D$ and $E$ social level consumers. 


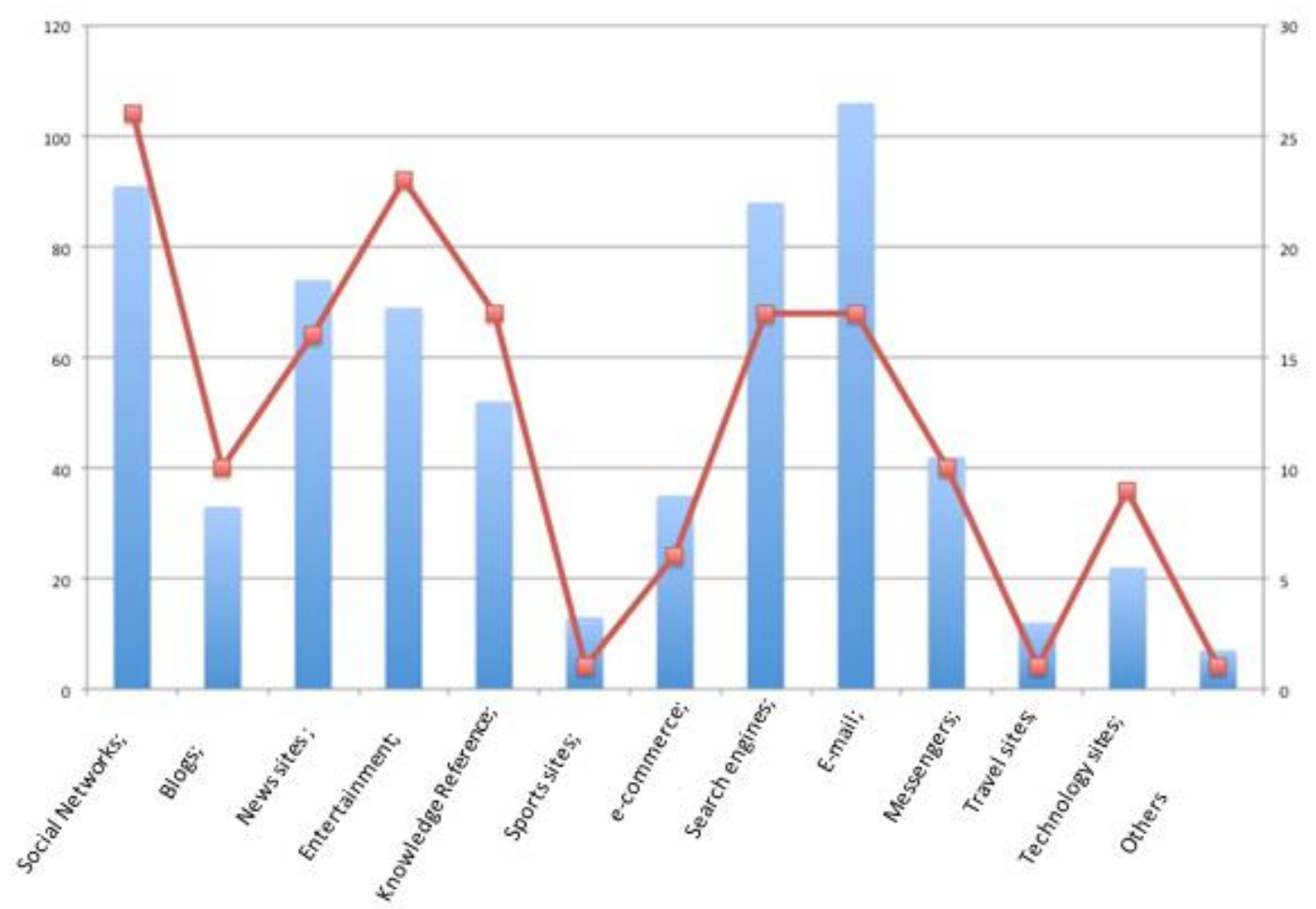

\section{Graph 9: On-line service categories deemed essential by the total universe and by the group of C, D and E social level class youngsters.}

The social network category peaks as most important for youngsters of the C, D and E social class levels whilst the universe total deems the same the second most important. Blogs show up above the total universe average as the seventh most important service for this same group of youngsters, reaping the market share of access to news sites, in an inverse proportion. Although blogs do not appear amongst the most relevant essential services per previous assessments, Brazil is the country that presents the highest percent outreach of the blog category amongst world surfers - 95,9\%. This might indicate that the blog is not a destination in itself and that what surfers seek are articles that they deem relevant, written by people who have captured their credibility and it doesn't really matter if one is accessing a blog or who the blog carrier effectively is.

In the news site category, the greatest access concentration involves people aged 35 to 44 years, who use news sites three times more than surfers aged 45 or more years and twice more than youngsters aged 19 or less. Entertainment sites in turn, show up as the second most relevant for youngsters of $C, D$ and $E$ social classes, well above the universe total's average and, according to 
Comscore (2011), far more than the world average of $88.6 \%$, featuring $97,5 \%$ reach out.

Reference sites (Wikipédia, Yahoo! Replies) containing information, questions and answers posted by consumers themselves appear amongst $C, D$ and $E$ class level youngsters as being far more relevant than the universe total's average.

According to Comscore (2011), e-commerce appears as being of little relevance; however, the category's outreach Brazil is far above that of the world average and of neighboring Latin American countries: 87.7\%. Nevertheless, despite high reach out, Comscore data indicates that, much like the results of the survey conducted by the authors, engagement and time spent on e-commerce in Brazil is effectively much less (32.5 minutes) than that encountered in other countries (United Kingdom: 133.2 minutes) and of the world's average (71.3 minutes). The authors were not able to identify in the research the reasons underlying current low engagement or the potential growth of this category amongst C, D and E social levels. However, cultural aspects, trust in the on-line purchasing process and availability of credit amongst others may represent the start of the engagement curve for the researched audience, a matter that shall have to be investigated in the near future under a new study. What effectively can be identified according to Comscore (2011) data is that, within the ecommerce category, Mercado Livre appears amongst leading sites with 14 million users per month. This site is also a platform whereby users themselves place products for sale whilst others purchase, indicating that Web 2.0 platforms can be of major relevance across multiple segments.

Search engines appear below average figures when it comes to social class $\mathrm{C}$, $D$ and $E$ youngsters, indicating a potential change in primary information search source behavior, a search tool transition movement to networks of collective knowledge such as social networks and reference sites when looking for content. The same applies to e-mails whose relevance amongst youngsters pitches drastically. One of the survey respondents explained what drove him to accessing his preferred social network: "Through Facebook, chatting with friends in common becomes faster than via e-mails". This indicates a change in both email use behavior and relevance, as a means of dialogue between acquaintances 
and friends. For youngsters, this objective is addressed by social networks and messengers.

Travel sites amongst youngsters appear well below the universe total irrespective of the fact that last year the category expanded $42 \%$. Technology sites show up with a far higher average which might suggest that the increase in socially lower class income enabled unprecedented access to technology goods and an increase in interest in the category itself. This assumption is reinforced by the high number of youngsters from classes C, D and E who own phones with internet access.

\subsection{SITES WITHOUT WHICH ONE CANNOT LIVE (OPEN ANSWER)}

In both the total universe as amongst classes C, D and E youngsters, Facebook appears as the most important site for Brazilian consumers, followed by Google; however, there are some differences between the total universe and youngsters of classes C, D and E, namely: Gmail is substituted by Hotmail, Yahoo appears as the strongest portal instead of Uol and Orkut, although the latter still appears with certain level of prevalence.
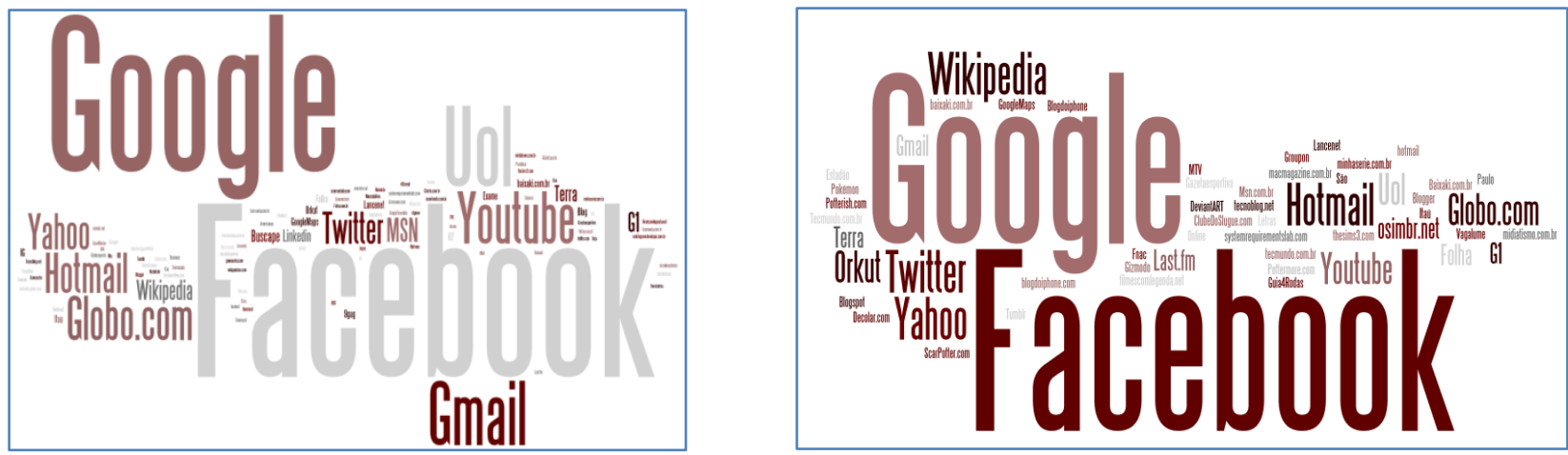

Figures 1 and 2: Cloud of words with greatest recurrence in the total universe (left) and in the class $C, D$ and $E$ youngster group (right) replies 


\subsection{MOST ATTENDED SOCIAL NETWORKS}

Survey findings as to the most popular social networks are similar to those published by Comscore concerning social network access and are pictured in Graph 2. Results further suggest that the number of accessed social networks is smaller at age ranges as of 35 years old, indicating greater use of multiple social networks amongst youngsters.

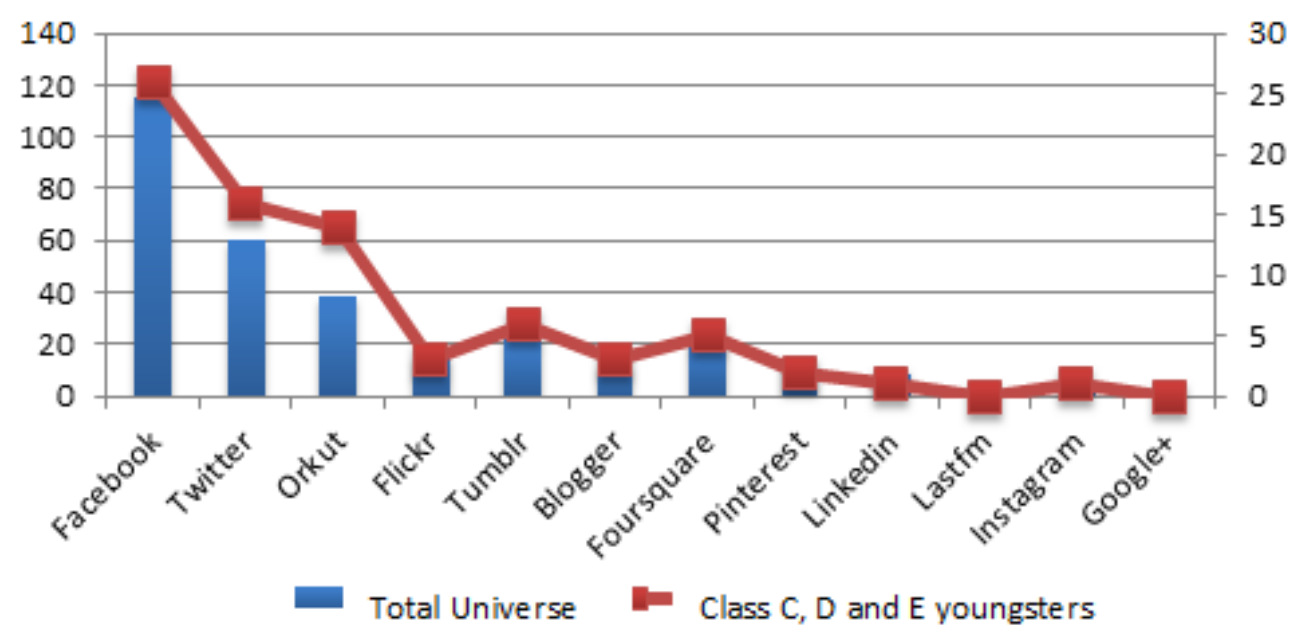

Graph 10: Attendance at Social Networks: total universe and social classes $C$, D and E youngsters

\subsection{FOR WHICH REASONS DO YOU MOST ACCESS YOUR PREFERRED SOCIAL NETWORK?}

For both the total universe and youngsters of classes $C, D$ and $E$ friends appear as the strongest reason but in the latter group, a greater plurality of social networks appears, in alignment with the results of the previous question, Family members also appear with relative importance. 

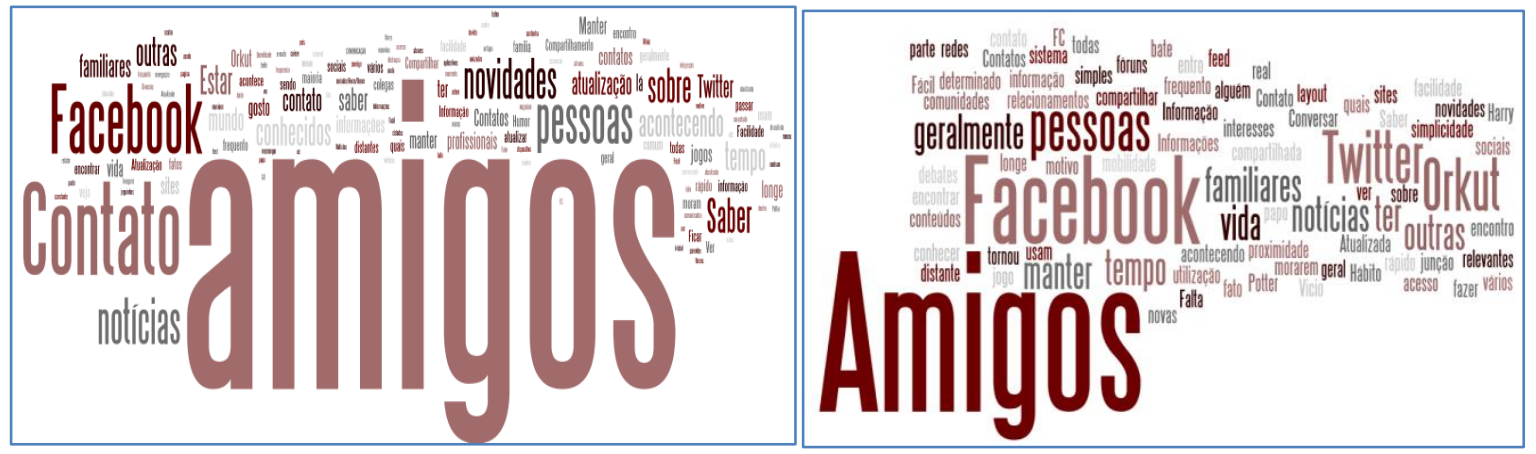

Figures 3 and 4: Cloud of words with greatest recurrence in total universe (left) and youngsters of classes C, D and E (right) replies

\subsection{MAIN ACTIVITIES THAT GENERATE MOST INTEREST OVER THE INTERNET}

There weren't any significant changes involving the three main activities for both the total universe and social level C, D and E youngsters but for the latter, listening to music appears in a stronger manner than that deemed average. Posting videos and photographs, playing games and meeting new people also appear with above average scores. Results further suggest that the number of activities of interest over the internet is greater for youngsters aged 19 or less $(5,3)$ followed by a significant reduction (between 4,1 and 4,5 ) in the 20 to 44 year range, whilst those who have least activities of interest on the internet are people aged 45 or more $(3,5)$. This decrease might indicate that interest tails off with age as time becomes increasingly scarce or that this new generation of youngsters presents greater engagement with the internet. This calls for recurrent surveys investigating the evolution of average use as this segment ages. 


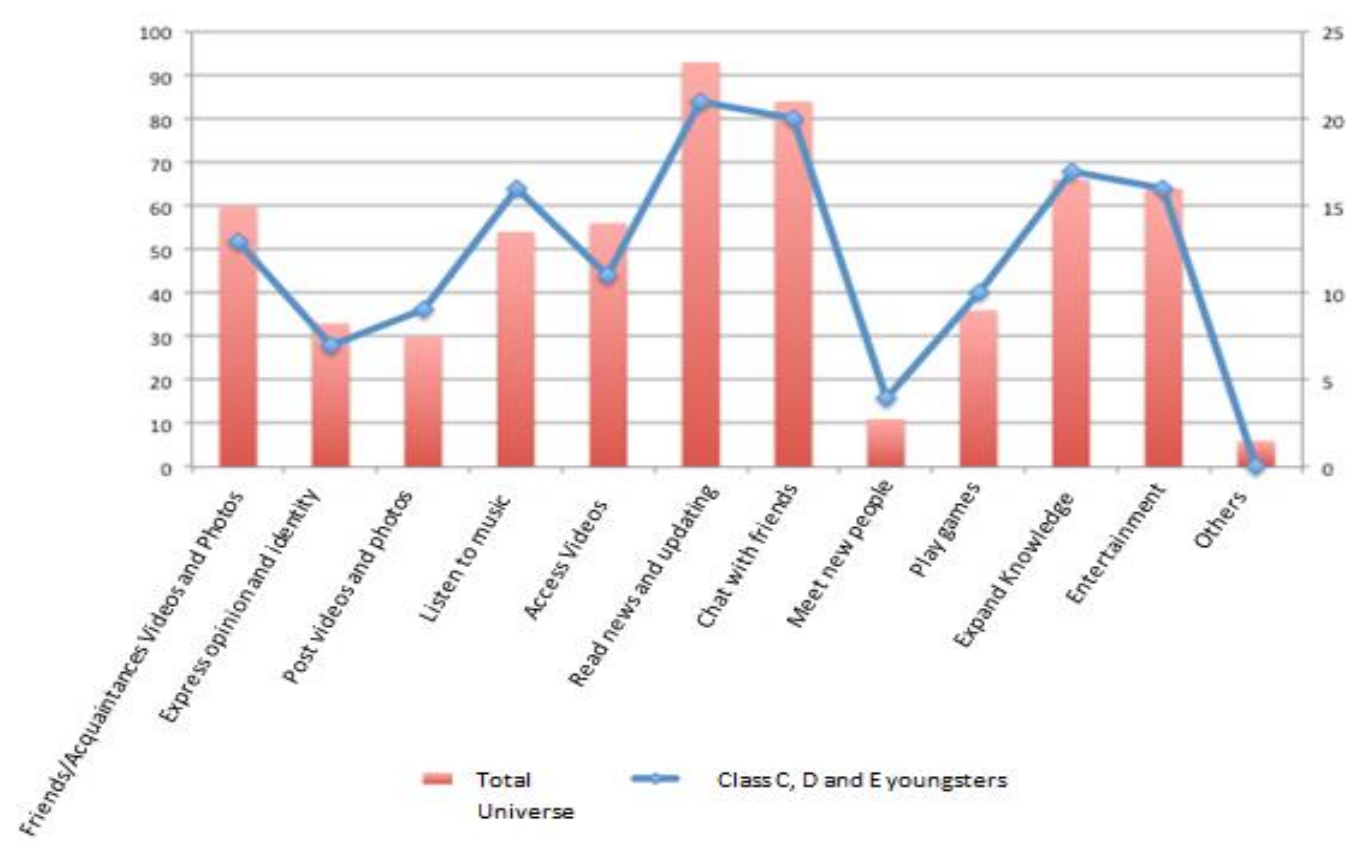

Graph 11: Prime interest activities over the internet: total universe and youngsters of classes $C, D$ and $E$

\subsection{MAJOR FORMS OF ENTERTAINMENT WITHIN AND BEYOND THE INTERNET}

Youngsters of social class levels C, D and E are highly engaged with music, in alignment with the total universe. However, findings reveal greater engagement with games than that deemed average and this ends up being the second most preferred form of entertainment of this segment. Videos, travel and sports, as mentioned in item 4.3, were found to be less relevant.

Entertainment modes average per person remains in and around three for all age groups but changes according to family income ranges: those with incomes between $R \$ 5000,01$ and $R \$ 7.500,00$ present the highest average interest in entertainment services ( 4,2 forms of entertainment) and the group that least consumes these is that of social classes C, D and E (between 3,3 and 2,4), suggesting that there is less access to entertainment activities besides internet for these classes and consequently less entertainment activity. 


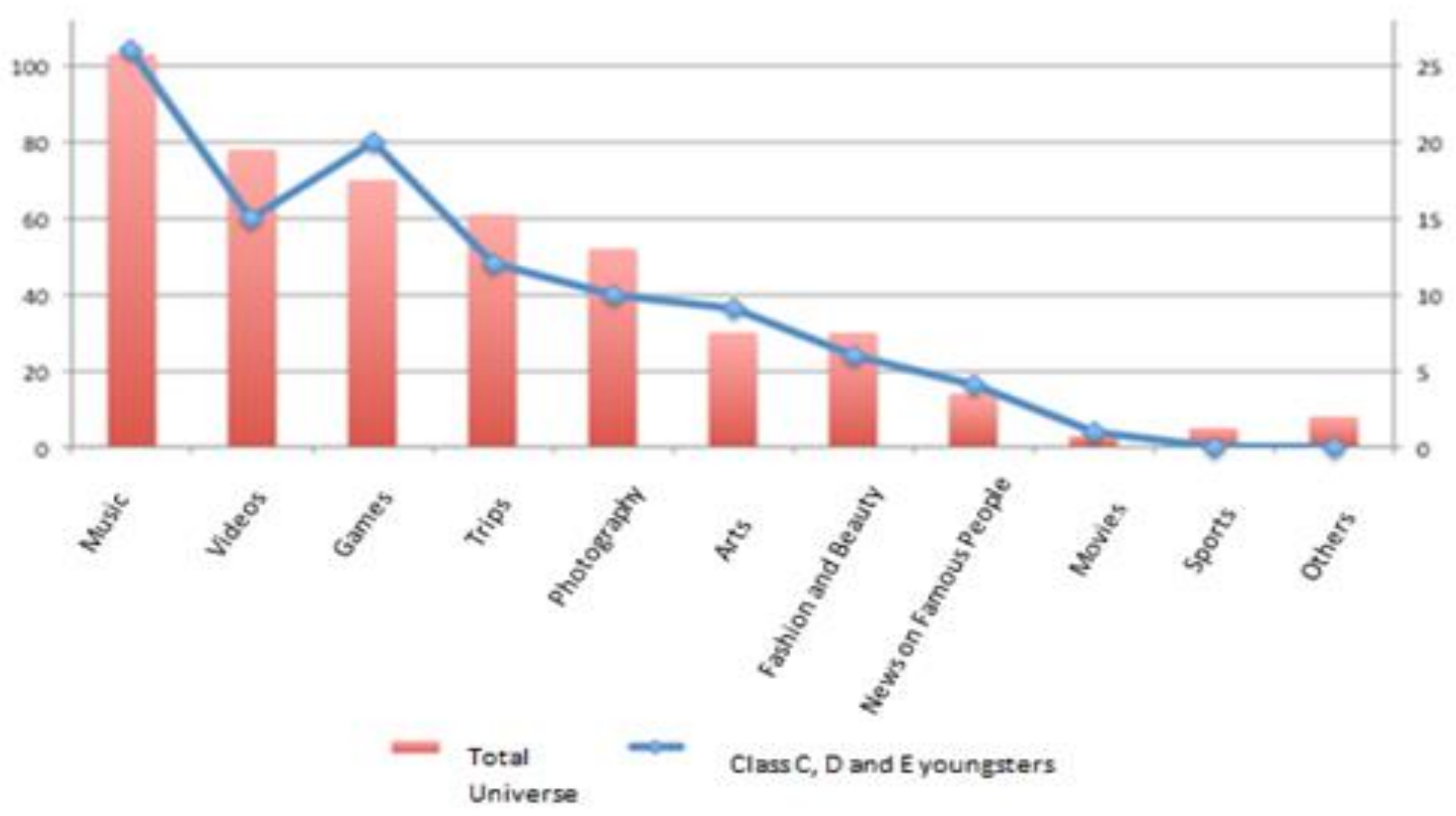

\section{Graph 12: Entertainment modes of greatest interest within and beyond the internet: total universe and youngsters of classes $C, D$ and $E$}

\subsection{REASONS TO ACCESS THE INTERNET}

Entertainment appears for both the total universe and youngsters of C, D and E social levels as the most important item. For the remaining items differences are bleak in terms of relevance except for increasing knowledge and making new friends which despite not being one of the main needs, was found to appear above the total universe average. 


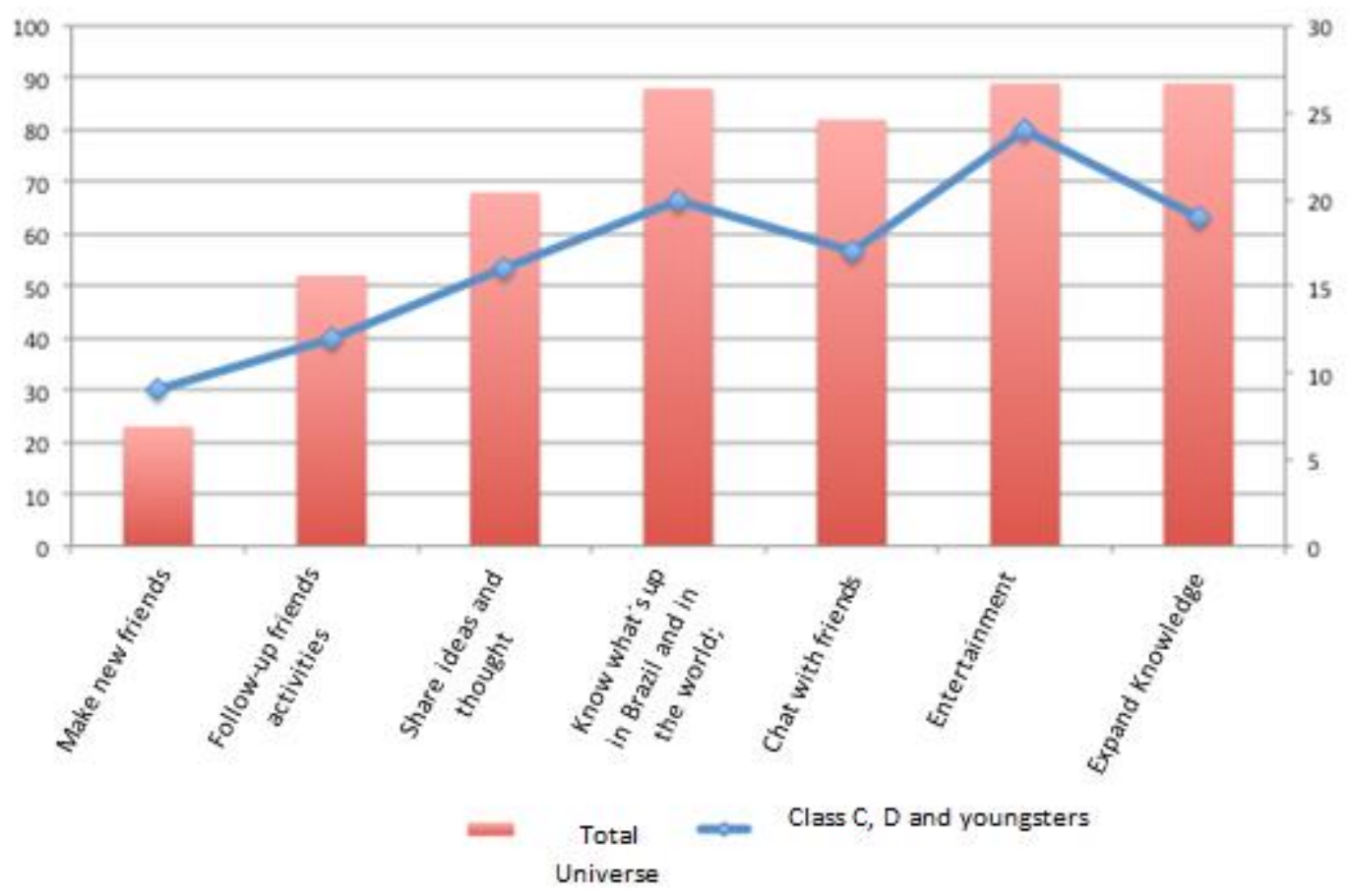

Graph 13: Main reasons to access the internet: total universe and youngsters of classes $C, D$ and $E$

\subsection{PRIME LIFE VALUES}

Education emerged as the most important need of class C, D and E youngsters; recognition and family together are the second most relevant value and work appears way above averages; popularity appears in alignment with youngster's collective need as a whole; express identity emerges at a lower level as compared to class C, D and E group totals, who generally present a greater need to express identities. 


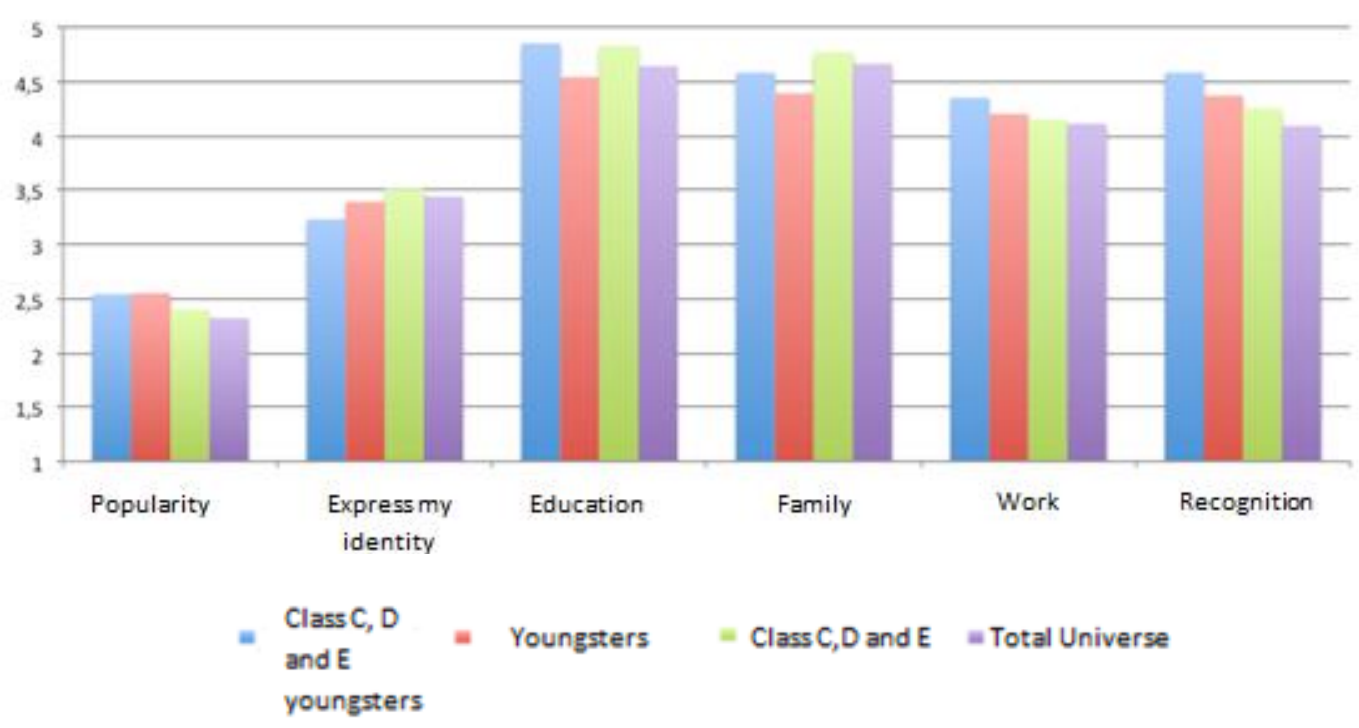

Graph 14: Major life values: total universe, youngster group, class C, D and $E$ group and youngsters of classes $C, D$ and $E$.

\subsection{WHAT MATTERS WHEN ACCESSING WHAT IS OF YOUR INTEREST}

To be able to clarify doubts with friends emerges as being extremely important and above average, followed by reading information published by renown journalists which likewise appears way above average; however, for youngsters, to consume content generated by other surfers, whether in the form of blogs, social networks or sites is less relevant than that published by renown channels but still above remaining group averages, in alignment with findings resulting from question 4.3. There are few differences in terms of value between the opinion of friends and that of people outside social circles, indicating that for Brazilians, the relevance of the message is not significantly reduced outside of one's group of friends. Although slightly higher than the opinion of friends, the difference is barely sensitive, suggesting that the value of an opinion is not weakened by the announced format as bonds tail off. 


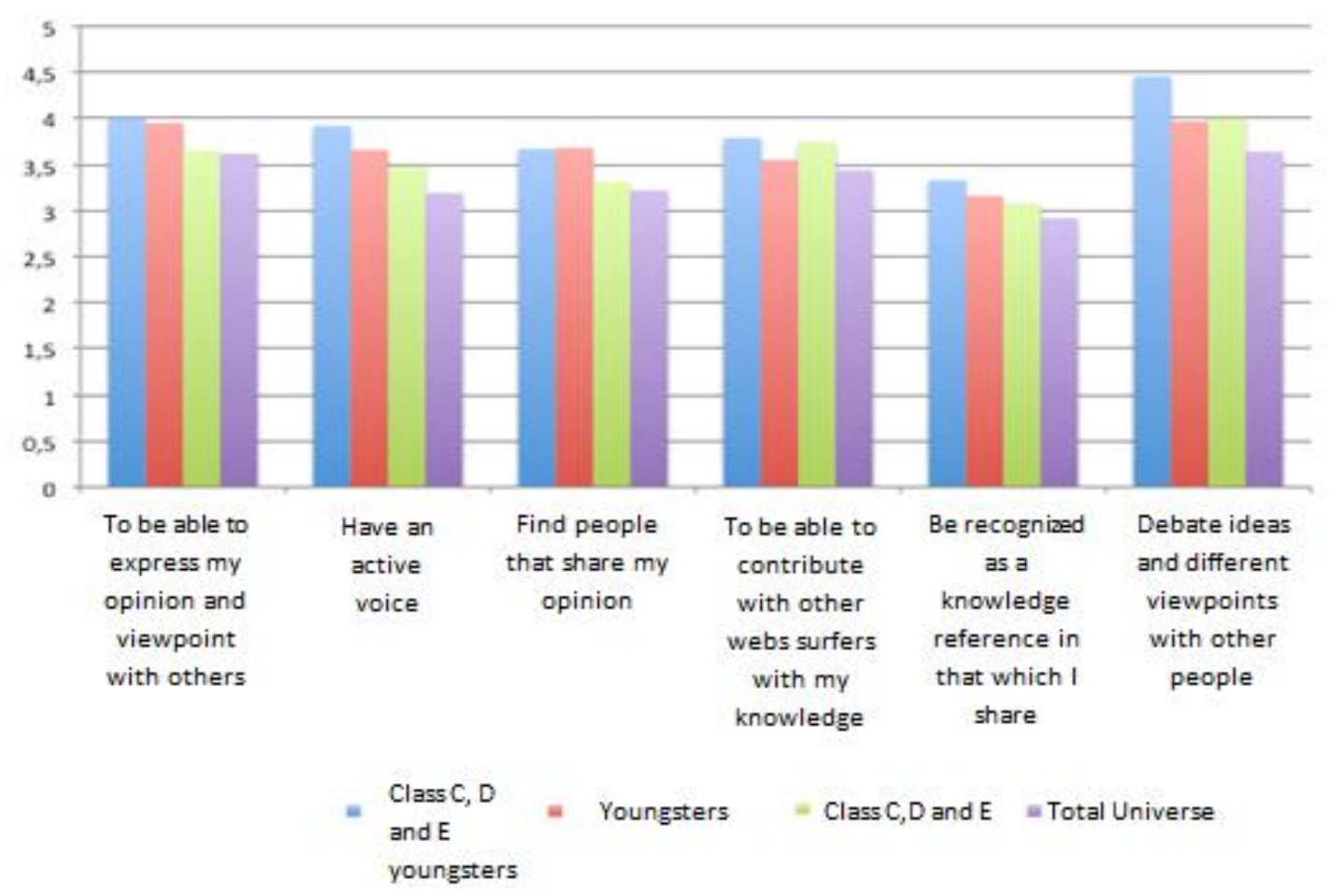

Graph 15: Expectations when accessing that of interest over internet: total universe, youngster group, class C, D and E group and youngsters of classes C, D and E.

\subsection{SHARING OPINIONS, RECOMMENDATIONS AND COMMENTS}

Amongst motivations to share, discussing one's point of view with others emerges as that most important, followed by being able to express one's opinion. Exercising an active voice appears as third most relevant further to the fact that it figures way above average.

Graph 16: Prime reasons to share opinions, recommendations and comments over the internet: total universe, youngster group, class C, D and $E$ group and youngsters of classes $C, D$ and $E$ 


\subsection{CONSIDERING THE ITEM DEEMED MOST RELEVANT IN THE}

PREVIOUS QUESTION, WHAT IS THE MOTIVATIONAL DRIVER (OPEN QUESTION)

People, express one self, knowledge and opinion emerge as prime reasons within the total universe. However, for youngsters of classes C, D and $E$, although the same items show up, knowledge appears as being far more important.

These results suggest that what drives a consumer to communicate over the internet relates to seeing and being seen by people by means of generating and consuming knowledge, expression, to be able to negotiate with other surfers and on-line identity given expression and personal opinions.

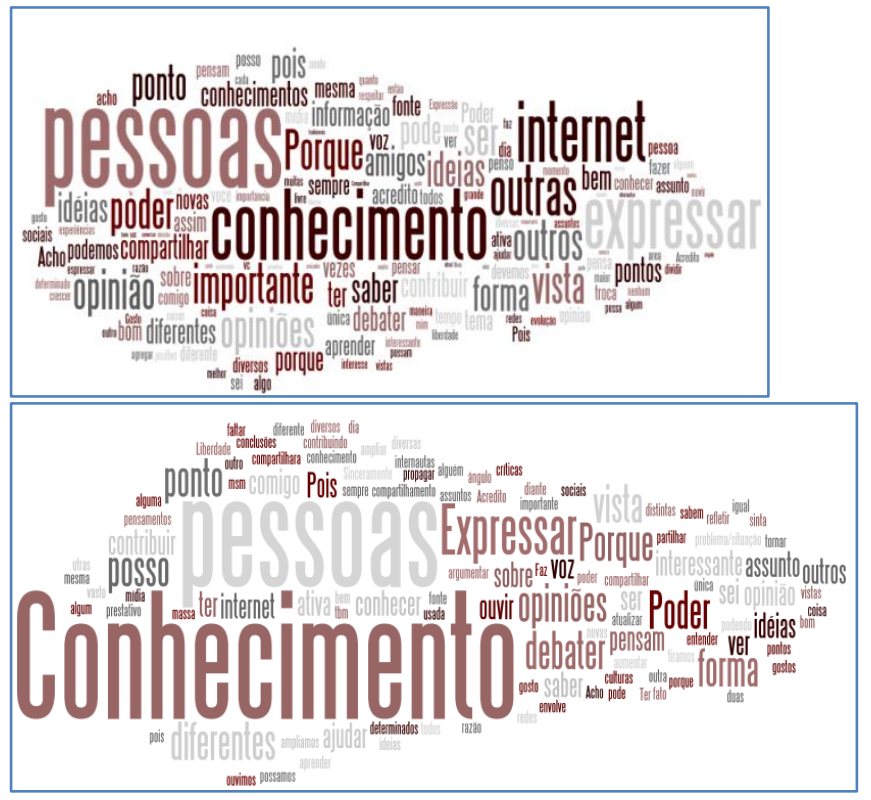

Figures 5 and 6: Cloud of words that most recur in replies: total universe (left) and class C,D and E youngster group (right)

\section{FINAL CONSIDERATIONS}

In light of research results and of theoretical references, major findings were both identified and consolidated into eight prime conclusions and recommendations, henceforth described. 


\subsection{FRIENDS AND PEOPLE THAT ARE AT THE CORE OF THE EXPERIENCE AND ABILITy to DISSEMINATE THE MESSAge AND OF MOBILIZATION ARE VERY HIGH}

Results and data indicate that the relationship and interaction with friends are at the core of relevant internet activities in Brazil. Media and companies that determine content and its relevance are losing space to the web surfers themselves who define their opinions. The level of engagement, in conjunction with the high average number of friends Brazilian surfers have, plus the need to express oneself - youngsters of the base of the pyramid in particular - leads to an exponential potential of dissemination of individual expression amongst those who form one's network; nevertheless, this outreach potential and relevance outreach continues to be deemed amazingly high when considering beyond one's group of friends figures.

Results enable the observation that bonds do not become sufficiently weak for messages to no longer be disseminated - inclusively outside one's group of friends - as long as a connection with the receptor's values and interests remains. This helps explain phenomena over Twitter whereby hash tags of Brazilian mobilizations often appear amongst the top world tweeted (as was the case of \#calabocagalvao for instance) and also because surfers enjoy boasting when they enter rankings of the most tweeted: i.e, collective recognition.

Furthermore, from results one notices that there are no indications that greater engagement over internet reduces personal relations and real contact. Virtual contact, according to findings, predominately occurs with people youngsters of the pyramid base also have contact with, in real life: acquaintances, friends and family members. The need to seek new people over the internet, despite being slightly higher amongst youngsters of the base of the pyramid, is still low as compared to other needs. Furthermore, one notices that the internet adds dynamics to existing relations, increasing the intensity, narrowing distances and maintaining dialogues continuously active. 


\subsection{PEOPLE INSTEAD OF ALGORITHMS TO DISCOVER ACTIVITIES}

Amongst youngsters of the surveyed pyramid base, the remaining web surfers and friends prove to form the core of internet and this audience or segment strongly trusts those within and beyond groups of friendship. The trend towards people becoming the center of discoveries reduces the relevance of search engines amongst consumers at least in as much as the discovery of forms of entertainment is concerned given it is the second most important activity for this segment of youngsters. Research and search sites still are of major relevance but no longer pose as the absolute starting point on on-line experiences as was once the case, given the rise of new ways of arriving at content of interest.

No matter how good the search algorithm is, it still does not substitute the synergy of interests a consumer has before friends and family members, and to this effect YouTube is an example. According to Comscore (2011) in December 2011 YouTube reached $83 \%$ of Brazil's internet whilst the overall average in Brazil amazingly peaked 109 videos per user/month and 10.6 hours/month spent on videos on this site, reaching an average of 156 videos per user/month within the young 15 to 24 year old men segment. Despite this level of significance, YouTube still did not configure itself in the survey as one of the main destinations without which consumers cannot live. The recorded behavior suggests that consumers do not enter YouTube to look for a video and enjoy themselves directly but rather, arrive at the video given indications of what friends are watching and recommending over social networks.

\subsection{INTERNET BRIDGES GAPS INVOLVING FORMS OF ENTERTAINMENT AND KNOWLEDGE}

Much like as unveiled amongst youngsters of the base of the pyramid, entertainment forms averages are minor as compared to the rest of the universe. This deficit is being compensated for over the internet since access barriers to on-line entertainment crumbles to zero as of when consumers have at least one point of access. According to Comscore (2011) the entertainment category 
reached by the end of $2011,97,5 \%$ and is at the core of this segment's interests. Furthermore, amongst these consumers, games arise as the second most desired form of entertainment, well above the overall average.

The same occurs with knowledge which arises as a very strong need for youngsters of the pyramid base so as to also bridge a gap involving real world access to knowledge. We find it of interest to validate that youngsters seek the opinion of other people, so as to obtain recognition and exercise an active voice and to reply to the doubts others raise, forming a social network of assistance to mutual knowledge. This is the underlying reason for services such as Yahoo! Replies to feature such an atypical performance in Brazil to the extent of leading the category in the country. This behavior allows web surfers to directly consult other people instead of using search engine services.

\subsection{INTERNET AS CONTENT LOSES SHARE TO INTERNET AS A PLATFORM}

Pierre Lévy and Lemos (2010) stated that status distinctions between consumers, editors and managers are reduced over Web 2.0, whereby at any given moment each may play the role they desire. In social computing, control roles are no longer mediated by traditional cultural mediators but rather return to the hands of mass audiences. It is up to the individual to categorize, organize, praise or reject content and to organize information in a collective manner.

Traditional information gatekeepers lose relevance and this is a matter of attention for a significant portion of large Brazilian companies that operate and innovate over the internet since these organizations are engaged in the field of generating content, not platforms. This takes place because most often they are digital branches of traditional media companies. There is no indication that news and content sites shall disappear, but rather, are at risk of following YouTube's tracks: not being a destination in themselves and thus their news sites begin to lose relevance as a destination. Their very discovery ends up taking place by means of the filter of what friends are seeing and recommending. This transformation is already in course given that the number of portals mentioned amongst sites without which youngsters of the base of the pyramid cannot live without was far less than that verified in the total universe. 


\subsection{NEED TO INVOLVE CONSUMERS IN THE PROCESS}

One must involve the consumer in the generation of content, as figures relative to the outreach of the blog category amongst Brazilian web surfers suggests. What one verifies is that the vast majority of Web 2.0 platforms that are relevant in Brazil are not produce of local companies. Yahoo! Replies and Orkut are sound proof that a platform can become a local success even if it is not a world preferred platform.

Large on-line companies in Brazil such as the digital branches of traditional media may fear losing relevance as consumers generate content and opinions themselves, replacing them. However the process is in full force and surveys have not unveiled indicatives of reductions in progress. There is an immediate need for these companies to not only develop editorial content but also platforms for web surfers to self-rule the generation, opinion and relevance of contents, offering the consumer tools that generate both recognition and status.

The consumer wants to have an active voice and involving them in the process increases the risk of the unexpected and unwanted arising. Nevertheless it also increases not only corporate learning processes but fosters a greater understanding of target audiences, in addition to gathering distinct opinions and establishing sound, comprehensive and accredited debates, which in turn serve the purpose of restoring amongst consumers lost credibility concerning traditional media .

Several companies add comment sections to news on their sites but this is not enough because consumer opinions remain on the outskirts of news, as if they were footnotes. On the other hand, interesting crowdsourcing journalism initiatives emerged in the US such as the Huffington Post. These may be replicated by means of local platforms to add the web surfer's opinion within articles, thus not remaining marginal to the same. However, the greatest challenge is not that of creating systems and platforms but mostly of changing culture within media groups that feel threatened once having lost the status of gatekeepers, i.e., of what should or not be published or deserves the spotlight. However, if these companies do not promote changes, others shall, since the process itself proves to be irreversible. 


\subsection{EVOLUTION OF THE SPEED OF COMMUNICATION}

Much like at the start of internet services sites were unilateral, mimicking printed media and overlooking the exploration of online interactive differentials, e-mail solutions which date back to the early stages of the internet, mimicking mail to the extent that this is explicit in its very name, electronic mail giving rise to a term which ultimately results from the simple addition of an "e" (as in electronic) to the name of traditional mail.

However, amongst youngsters of the pyramid base that present superior engagement and spend more time on social networks, e-mail loses penetration since it makes communication between youngsters, "slow". E-mail follows a text structure, much like a letter and requires a complete, structured message before being sent. The message has an introduction, a core and an end and is built and sent as a whole to the recipient. This was relevant at the start of internet since on-line access was effectively somewhat restricted and e-mail enabled consumers to download them off-line, read messages calmly, prepare a reply and send it the next time they plugged in and accessed the internet.

If one agrees that letters progressed into e-mails, social networks and messengers play a similar role when it comes to dialogues and, given that youngsters have more points of access and are more engaged than other segments, conversation time distances are increasingly reduced, further enabling uninterrupted dialogues. For this group that are newcomers to the Brazilian internet, expectations are that e-mail for personal use purposes shall increasing be dropped; however, it still remains strong amongst previous generations both because it is already consolidated and embedded and given the smaller level of on-line engagement in social networks as compared to the segment of youngsters.

E-mail presence in the future corporate environment is somewhat difficult to forecast given that professionally, there is a need to formalize and structure communication and there is no alternative solution that addresses such corporate needs. There are start-up initiatives to build a substitute for corporate e-mails however to date the conclusion of this effort is that no service has been able to take the lead in terms of outreach, efficiency and relevance. 


\subsection{INTERNET IN THE POCKET OF PYRAMID BASE YOUNGSTERS}

Although data and research was not oriented to mobile devices and their specific use, findings indicate that these offer the potential to transform themselves into the predominant access to internet platform in Brazil given its existing high penetration in the pockets of pyramid base youngsters in comparison to the total universe.

Mobile phones enable new uses of internet services given that they add to the equation mobility and geographic information as to the consumer's whereabouts via GPS. Thus, one may combine opinions and interests with their current geographical location, bringing new service possibilities based on location, such as regional news, recommendation of local services, stores and products in the vicinity, nearby people and friends, sites of interest, surrounding recommendations made by friends and geo-location media. For instance, at lunch time one may receive an ad from the region the consumer is at about a restaurant that serves the type of food he or she likes with recommendations from friends and other web surfers as to the restaurant's offers and services.

\subsection{NEXT STEPS FOR COMPANIES TO OPERATE ON-LINE IN BRAZIL}

Given the lack of entertainment options for youngsters of the base of the pyramid and in light of Brazilian social peculiarities, entertainment shall continue to be in the near future the predominant portion of the entire message dissemination and social mobilization potential. As entertainment options consolidate and current deficits and absences are overcome, the required conditions for the rise of a collective conscience in terms of mass social construction may emerge. However, there is no sound indication as yet suggesting this will take place on a large scale basis in the near future unless a truly relevant massive disruptive event occurs.

Findings demonstrate that the Brazilian internet not only is highly adherent to the Web 2.0 phenomenon but also that the level of engagement consumers enjoy with the web as a platform is extremely high. When one compares the needs of the base of the pyramid as per Prahalad (2009), there is little or no 
difference in relation to the Web 2.0 concept that provides access at low costs (once the first point of access to the same is established), enables an active voice, democratizes access to information, transforms consumers into microproducers, gives rise to ecosystems, to the co-creation of solutions and to scalability.

This sum of variables is reinforced by local social-cultural characteristics such as the search for independent opinions given the erosion of traditional media credibility and the virtualization of friendships, spruced an extremely high level of vocal power and on-line message dissemination in the country. Once to this statement one adds the fact that Brazil features as the seventh largest on-line population, a unique lab for user assimilation distribution and critical mass is shaped, involving initiatives that place the consumer at the core and grant the same an active voice plus recognition.

Thus, herein rests an opportunity for local companies to innovate and ideate platforms that offer this vocal power to youngsters of the base of the pyramid and which, once established, should not be restricted to the local market given that these skills can be leveraged to other countries featuring similar characteristics. This is fostered by the fact that entry barriers for global distribution over the internet are practically non-existent. Nevertheless, this possibility has hardly ever been explored by local companies that continuously focus on the domestic market and currently sit back and watch their space and relevance dissipate to platforms built by global companies. 